\title{
Folkers, bardos e barbados: memória, utopia e política no medievalismo brasileiro ${ }^{1}$
}

\author{
Marco Antonio Bin \\ Doutor em Ciências Sociais pela PUC-SP. Integrante do Grupo de Pesquisa em Memória, \\ Comunicação e Consumo (MNEMON) do Programa de Pós-Graduação em Comunicação e \\ Práticas de Consumo da ESPM. \\ E-mail: marcobin@gmail.com \\ Mônica Rebecca Ferrari Nunes \\ Docente e Pesquisadora do Programa de Pós-Graduação Stricto Sensu em Comunicação e \\ Práticas de Consumo PPGCOM-ESPM. Lider do Grupo de Pesquisa MNEMON, Memória, \\ Comunicação e Consumo (CNPq/ESPM). \\ E-mail: monicarfnunes@espm.br
}

Resumo: Este artigo é parte de uma ampla pesquisa sobre o medievalismo brasileiro praticado por grupos jovens que se reúnem presencialmente para combates, piqueniques, festas e feiras, cuja inspiração é o período medieval. O objetivo deste trabalho é demonstrar como a memória produzida nestes grupos revela dimensões utópicas e políticas geradas das urgências do tempo presente. A metodologia se vale de pesquisa etnográfica (flânerie), por meio de pesquisa de campo em eventos realizados por estes grupos, especialmente na cidade de São Paulo, e bibliográfica a partir dos estudos da semiótica da cultura e da mídia, das teorias sociais e da memória, assim como do estudo das teatralidades juvenis.

Palavras-chave: memória; medievalismo; utopia; política; juventude.
Abstract: Our article is part of an extensive research on the Brazilian medievalism practiced by young groups that meet face to face for combats, picnics, parties and fairs, whose inspiration is the medieval period. The objective of our study is to demonstrate how the memory produced in these groups shows utopian and political dimensions resulting from the urgencies of the present. The methodology is based on ethnographic research (flânerie), by field research, and bibliographical research, supported by studies of semiotics of culture and media, social theories and memory, and the study of theatricality.

Keywords: memory; medievalism; utopia; politcs; youth.
1. Trabalho apresentado ao Grupo de Trabalho Memória nas Mídias do XXVIII Encontro Anual da Compós, Pontifícia Universidade Católica do Rio Grande do Sul, Porto Alegre (RS), 11 a 14 de junho de 2019.

Recebido: 20/12/2019

Aprovado: 11/02/2020 


\section{INTRODUÇÃO}

A pesquisa com o medievalismo brasileiro, especialmente com coletivos jovens que encenam práticas lúdicas, comportamentos e rituais atribuídos à era medieval, participa de nosso escopo investigativo há algum tempo ${ }^{2,3}$. Realizamos pesquisa de campo seguindo a metodologia da flânerie, normalmente nos locais em que eles se reúnem, seja em eventos mais diversificados, tais quais o Anime Family ${ }^{4}$, como o que frequentamos na cidade do Rio de Janeiro, ou temáticos, como o Banquete Medieval Schola Militum ${ }^{5}$, em São Paulo. Nossas incursões nos levaram a perceber como os jovens codificam e textualizam esse período histórico construindo memórias articuladas ao consumo e às mídias.

As memórias do medievo aparecem não só em narrativas como quando relatam oralmente as lendas arturianas que inspiram a formação de suas escolas de combate. Essas memórias são encadeamentos simbólicos, codificam gestos de luta, vestimentas, alimentos, armas e uma série de outros objetos em textos, no sentido dos semioticistas de Tártu-Moscou, por sua vez apreendidos como medievais desde a infância, nos livros de histórias ou na televisão, nas produções da web e em tantas outras mídias e linguagens. Ao dizermos que um objeto pode ser um texto cultural, entendemos que ele é codificado de alguma maneira e, por certo, os códigos do medieval nos são desconhecidos, mas, pensando com Lotman, "teremos que os reconstituir, baseando-nos no texto que nos é dado" ${ }^{\text {. }}$

Lido por um conjunto de códigos diversos ou por um código único, o medieval se torna texto. Para Lotman, um dos traços distintivos do texto é sua extensão no tempo natural, outro traço é a tendência à pancronicidade ou a formar seu próprio tempo interno.

Circunscrevendo nossas observações a estes agrupamentos jovens, este artigo busca demonstrar que as memórias produzidas pelo medievalismo histórico ou midiático são teatralizadas e nestas teatralidades da memória um tempo textual se cria internamente, o tempo utópico, próximo à idealização, ao mito, às hierofanias. Entretanto, porque o texto e a memória podem ser pancrônicos, as urgências do tempo presente, neoliberal, incidem sobre o que é possível narrar e desejar. Inevitavelmente, aqui, o texto cultural atravessa-se do político, uma vez que "o político não se configura por problemáticas e temas, mas especialmente pela maneira pela qual se constroem as relações com a vida, com o entorno, com os outros, com a memória, a cultura e o artisticamente estabelecido"7.

Para tanto, desenvolvemos nossos objetivos com base em pesquisa de campo seguindo a metodologia da flânerie, como descrita por Peter McLaren ${ }^{8}$ : o pesquisador captura o sensorial do espaço e de seus entrevistados; as entrevistas seguem um roteiro vazado, com questionamentos gerais, porém livres de amarras categóricas; o registro narrativo potencializa o método. Neste artigo, apresentamos a coleta de depoimentos do $17^{\circ}$ Encontro Folk SP 2019, obtidas pela flânerie, e realizamos análise comparativa no que tange às dimensões utópicas e políticas das teatralidades da memória em relação a outros grupos
2. NUNES, Mônica Rebecca Ferrari. (org.). Cosplay, steampunk e medievalismo: memória e consumo nas teatralidades juvenis. Porto Alegre: Sulina, 2017.

3. NUNES, Mônica Rebecca Ferrari; BIN, Marco Antonio. Espartilhos e espadas: vitorianos e medievalistas em práticas juvenis. Revista Líbero, São Paulo, v. 19, n. 38, p. 69-80, 2016.

4. Anime Family é um evento de cultura pop japonesa organizado pela Yamato Corporation, cuja tônica é o encontro de fãs de animes, mangás, $\mathrm{HQs}$, séries etc. Nesses espaços ocorre a presença de medievalistas.

5. O Banquete Medieval Schola Militum é um evento criado para reproduzir os espaços de uma feira medieval, cujo ápice é o banquete que conta com shows de música medieval, apresentação de combates, venda de artesanato etc.

6. LOTMAN, I. La semiosfera. Madrid: Cátedra, 1996, p. 93

7. DIÉGUEZ, Ileana C. Escenários y teatralidades liminales. Prácticas artísticas y socioestéticas. Inquietando, [S. I.], 2016. Disponíve em: https://inquietando. wordpress.com/textos-2/ escenarios-y-teatralidades-liminales-practicas-artisticas-y-socioesteticas/. Acesso em: 14 fev. 2019.

8. MACLAREN, Peter. Multiculturalismo revolucionário. Porto Alegre: Artmed, 2000. 
9. Cf. Nunes e Bin (2016) e Nunes (2017).

10. ZUMTHOR, Paul. Performance, recepção, leitura. São Paulo: Cosac Naify, 2007.

11. DIÉGUEZ, Ileana C. Um teatro sem teatro: a teatralidade como campo expandido. Sala Preta, São Paulo v. 14, n. 1, p. 125-129, 2014

\section{DIÉGUEZ, Op. cit.}

13. ECO, Umberto. Viagem na irrealidade cotidiana Rio de Janeiro: Nova Fronteira,1984.

14. NAPPO, Sami A. De tabardo e espada em punho: consumo, memória e medievalismo em um grupo juvenil praticante de boffering. 2017. Dissertação (Mestrado em Comunicação e Práticas de Consumo) - Escola Superior de Propaganda e Marketing São Paulo, 2017. já investigados em nossos trabalhos ${ }^{9}$. Além da pesquisa de campo, há pesquisa bibliográfica centrada na Escola de Semiótica de Tártu-Moscou, em teorias sociais e da memória, bem como em autores que discutem teatralidade e performance.

A seguir, apresentamos as teatralidades da memória do medievo, a cena utópica, medievalismo e política.

\section{FOLKERS, BARDOS E BARBADOS NAS TEATRALIDADES DA MEMÓRIA}

Denominamos as práticas medievalistas como teatralidades. São os trabalhos de Paul Zumthor ${ }^{10}$ e Ileana Diéguez ${ }^{11}$, com os conceitos de performance e teatralidade expandida e liminar, que ajudam a entender as memórias produzidas no medievalismo brasileiro. Para os autores, as teatralidades têm atravessado as disciplinas do Teatro e da própria arte-performance, porque participam das ruas, dos ativismos, das intervenções urbanas "e se instalam em um espaço de travessias, liminalidades, hibridações, de onde se cruzam e se interrogam os campos da arte, da estética e o político" ${ }^{12}$.

A ideia de teatralidade expandida - isto é, que não se reduz à cena e tampouco à interpretação de um roteiro - é válida para entender a performance de gestos e atos, músicas e palavras, a feitura de vestimentas e todos os vestígios mnemônicos de um medieval inventado, mas nem por isso desimportante ou menos real. Aqui a teatralidade é a da vida atravessada pela ficção, uma vez que jovens barbados travestidos em bardos têm suas trajetórias pessoais de desemprego ou empregos precários, estudos interrompidos, sonhos, desejos, e dão vazão a seus imaginários tecidos também por representações midiáticas idealizadoras de um longo período histórico ressurgido na cultura pop e midiática desde os anos $1970^{13}$.

Assistimos a um desfile de trajes peculiares como tabardos, túnica longa destinada a guerreiros antigos, cotas de malha, elmos, escudos, grandes orelhas pontiagudas e uma infinidade de objetos compondo ambiências e personagens: cavaleiros, princesas, elfos, e divindades de finais de semana. Grande parte dos encontros ocorrem aos sábados e/ou domingos em parques citadinos, como os treinos e apresentações do grupo Draikaner de swordplay boffering, que se destina a interessados "em praticar a simulação de combates medievais em um ambiente de esporte e socialização", como descrito no site do grupo. Os combates são realizados com réplicas de armas da Idade Média, feitas de madeira, espuma e PVC. Reúnem-se no Parque Ibirapuera, em São Paulo. Outros encontros se dão em florestas urbanas, como a da Tijuca ou da Quinta da Boa Vista, na cidade do Rio de Janeiro, como o faz o Graal RJ Aventuras Improvisadas, que lá se reúne para a prática do live action role playing (Larp), modalidade do role playing game (RPG) inspirada em lendas medievais.

Esses grupos surgem em nosso país a partir dos anos $2000^{14}$ e, desde então, o número de fãs, performers e eventos da cultura medieval, como denominam, 
cresce expressivamente. O fenômeno é observado nas escolas de combate, como nos grupos Draikaner, Schola Militum, Graal RJ, Combate Medieval Brasil, entre outros, e em ambientes menos formais, como no Encontro Folk SP. Há também eventos de outra natureza, calendarizados, disponíveis na web, sejam anunciados em páginas específicas, como a Cena Medieval - "blog dedicado a concentrar informações sobre a cena medieval no Brasil"15 - sejam espalhados pelas redes socias anunciando amplo espectro de festas, shows de música, feiras, festivais gastronômicos, campeonatos de lutas etc.

Se já afirmamos que o medievalismo hoje pode ser expressão da cultura da memória, termo consagrado por Andreas Huyssen ${ }^{16}$ - entre outros pensadores que reconhecem a obsessão por lembrar como marca de tempos atuais -, também constatamos, por outros vieses teóricos ${ }^{17}$, que o passado está sempre presente num continuum semiótico, isto é, sígnico e textual. E os textos, dotados de memória, geram outros, dinâmicos no tempo. Nada nos parece mais equivocado do que compreender a memória como resgate de um passado marmóreo. A memória e os textos pancrônicos falam também ao futuro, a um projétil e o passado é constantemente recodificado e retextualizado, portanto, ressignificado.

Não há, necessariamente, culto à memória por medo do esquecimento ou da velocidade que a tecnologia impõe à vida cotidiana destruindo o passado, como advertiu Huyssen ${ }^{18}$. Os grupos estudados têm páginas na web, usam as redes sociais para marcar eventos, postam fotografias dos encontros, estão conectados. O passado aparece glamourizado e, no caso dos participantes da cultura medieval, teatralizar memórias significa "viver uma cultura que a gente admira" (Camila Postal) ${ }^{19}$, "viver alguma coisa que eu sempre gostei desde criança" (Leonardo Guimarães) ${ }^{20}$, dizem os entrevistados.

Independentemente das preferências e dos motivos para admirar o medieval, não duvidamos da mercadorização da memória e de que textos culturais medievalistas participam do cotidiano desses jovens: espalham-se em profusão em videojogos, séries, películas cinematográficas, HQs e tantas outras narrativas midiáticas. Os textos medievalistas vivem igualmente em espaços de consumo convencionais. Restaurantes, por exemplo, transformam a prática alimentar em consumo de experiência imersiva, como o fez o Taverna Medieval, na cidade de São Paulo, em que pratos e bebidas degustados, louças, decoração e atendentes nos fazem sentir em uma taverna como as narradas em filmes ou livros de aventuras. A casa também promove shows de bandas folks e medievais, assim como jogos de RPG de mesa, comandados por mestres vestidos a caráter que narram histórias em companhia dos clientes.

A imersão passa a ser elemento codificador para o consumo de experiências estimuladas pelo mercado, afeitas à cultura da memória, para pagar por espetáculo de música medieval em ambiente pouco iluminado, artificialmente frio, bebendo hidromel em caneca de pedra, e para a teatralização das memórias vividas pelos coletivos nos parques, de modo lúdico, livre e gratuito. Lemos na página do Facebook do Encontro Folk SP 2019: "levem seus instrumentos
15. Disponível em: http:// www.cenamedieval.com. br/. Acesso em: 19 dez. 2019. 16. HUYSSEN, Andreas. Seduzidos pela memória. Rio de Janeiro: Aeroplano, 2000

17. LOTMAN, Op. cit.

18. HUYSSEN, Andreas. Culturas do passado-presente: modernismos, artes visuais, políticas da memória. Rio de Janeiro: Contraponto, 2014

19. Informação verbal: entrevista sobre medievalismo concedida a Marco Bin e Mônica Nunes no $17^{\circ}$ Encontro Folk de SP, no Parque da Água Branca, em São Paulo, em 9 de fevereiro de 2019.

20. Informação verbal: entrevista sobre medievalismo concedida a Marco Bin e Mônica Nunes no $17^{\circ}$ Encontro Folk de SP, no Parque da Água Bran$\mathrm{ca}$, em São Paulo, em 9 de fevereiro de 2019. 
21. Disponível em: https:// www.facebook.com/folkerssp/. Acesso em: 19 dez. 2019.

22. DIÉGUES, Op. cit., 2016

23. PASSERINI, Luisa. Memoria y utopia: la primacia de la intersubjetividade. Valencia: Publicacions de la Universitat de Valencia, 2006, p. 18.

24. Disponível em: https:// www.facebook.com/folkerssp/. Acesso em: 19 dez. 2020.

25. DUBY, Georges. A Europa na Idade Média. São Paulo: Editora Brasiliense, 1988 . musicais, drinking horns, canecas, traje medieval não é obrigatório, mas aqueles que tiverem e puderem ir trajados a caráter, por favor, venham! Assim nosso encontro fica mais imersivo e renderá ótimas fotos!"21.

Fantasias, músicas e objetos funcionam como operadores para que "o encontro fique mais imersivo", nas palavras dos administradores da página; para nós, codificam as teatralidades das memórias do medieval. Nesse sentido, imersão e teatralização gozam de uma mesma propriedade: "um instinto de transfiguração capaz de criar um ambiente diferente do dia a dia, de subverter e transformar a vida" ${ }^{22}$. As rupturas do cotidiano, abertas pelas teatralidades das memórias do medievo, tornadas texto no tempo, instauram um pulsar utópico: o tempo interno da ficção.

Considerando a teatralidade como emergência da ficção posicionando os sujeitos em face de seus imaginários, sugerimos as conexões entre memória e utopia: o imaginário como forma de subjetividade compartilhada através do tempo e do espaço. Subjetividade acumulada, herdada da memória coletiva. Por seu turno, "a utopia se configura como impulso da subjetividade que assume uma posição orientada para mudança no processo histórico" ${ }^{23}$. Reconhecemos a utopia como uma das dimensões contidas nas teatralidades da memória do medievalismo.

\section{FLÂNERIE: UTOPIA POR UM DIA}

O convite aberto nas redes digitais nos estimulou a conhecer um evento denominado $17^{\circ}$ Encontro Folk SP 2019, no Parque da Água Branca. A convocatória na página do Facebook descrevia o conjunto das práticas culturais a serem promovidas: "a ideia é uma folk session open-air, dançar muito, conversar e fazer um grande piquenique", destacando a característica multicultural do encontro ao ar livre, em um local público voltado aos "admiradores de cultura nórdica, celta, pirata, Idade Média no contexto geral ou simplesmente admiradores da boa música folk, medieval, celtic, viking, pirate metal"24.

A matriz medievalista em sua abrangência histórica e midiática prevalecia na caracterização dos que vinham fantasiados. Eram guerreiros, cavaleiros, arqueiros, bardos e vikings que se misturavam às referências ficcionais da época, como faunos e elfos. Não é ao acaso a escolha do parque como lugar para realizar os encontros. Entendemos que este espaço pode representar simbolicamente as florestas, comuns ao cenário medieval. Lugar privilegiado da caça para a aristocracia e de sobrevivência para os desgarrados esfomeados ${ }^{25}$. Camila Postal, 25 anos, recepcionista em um Banco, formada em biologia e uma das organizadoras do evento, explica o motivo dos parques serem o palco do encontro: "o folk e o medievalismo pregam o culto à natureza [...], se você está aqui, você tem pelo menos um pouco de ligação com a natureza, você quer resgatar suas raizes; as culturas antigas sentem a necessidade de resgatar a ligação com a natureza”. O fato de ir caracterizada de guerreira não significa um vínculo com a personagem 
histórica, pois a cada novo encontro procura participar com fantasias que exprimam diferentes representações medievais. Perguntada se a prática do medievalismo constituiria uma forma de fuga da realidade, Camila respondeu que sim e não: "sim, é uma fuga da realidade que a sociedade nos impõe, e não, para não deixar a nossa realidade fugir da gente" ${ }^{26}$.

Não deixar nossa realidade fugir da gente talvez seja a afirmação mais esclarecedora desses grupos que encontram no imaginário, muitas vezes desconectados da historiografia canônica do longo período medieval, o tema ideal para a realização de seus prazeres, suas amizades e suas utopias. Em grupos, organizam maneiras de se vestir e de se encontrar, alimentando o atávico impulso humano de viver em sociedade. $\mathrm{O}$ fato de muitos estarem desempregados ou viverem uma vida de faltas apenas os estimula a vivenciar esses escapes coletivos de entretenimento e prazer, que por vezes atravessam a vida real. Tanto Camila como outro organizador do evento, Leonardo Guimarães, 34 anos, professor desempregado, têm nas práticas medievalistas realizadas nos parques uma maneira de manter contato com a formação acadêmica - a Biologia, no caso de Camila - e assim interagir o lúdico com uma escolha de carreira que, diante da conjuntura econômica, dificilmente encontrarão mercado de trabalho.

Próximos de nós, a banda em que Camila atua como vocalista, Mermages Acoustic Folk, composta por jovens barbados e com longos cabelos, orelhas de elfos e instrumentos xamânicos, ensaiava alguns acordes sempre ao lado de uma frondosa árvore, enquanto circulavam personagens díspares como o soldado romano, o cavaleiro arturiano, muitos jovens góticos vestidos de negro, em torno da mesa com alimentos e bebidas alcoólicas em abundância, algumas disfarçadas em pequenas garrafas.

Como coparticipantes, interagíamos com nossos aparelhos tecnológicos, interpelando os componentes do grupo e registrando em som e imagem a construção das memórias teatralizadas naquele espaço compartilhado com a natureza. Uma área mais isolada do parque servia como palco, caracterizando algo similar à performance de uma cena expandida, marcada pela encenação híbrida, sem atuação prevista, os atores intervindo ao mesmo tempo como espectadores de um roteiro aberto, sutilmente definida como medievalista, completamente desierarquizada, onde todos trocam sistematicamente de lugar para expor aquilo que não se sabe e que antecipadamente não se define ${ }^{27}$. Não pudemos deixar de perceber que quase todas as ações aconteciam em torno de grandes árvores: o canto, a dança, o piquenique, a leitura de contos. Inevitável não lembrar Mircea Eliade ${ }^{28}$ e suas descrições de rituais em torno do que muitas sociedades míticas consideram o centro do mundo: árvores representando o eixo cósmico que manifestam o sagrado e permitem a comunicação para o alto.

A leveza emanada pelo grupo folk talvez expressasse de modo bastante feliz o sentido do termo hierofania. As memórias do medievo ali manifestadas, com todas suas nuanças, apresentavam uma cosmologia em que as partes do universo estavam ligadas entre si pela presença da natureza e, aqui, o principal vínculo dos jovens com a Idade Média. Como nos diz Franco Junior,
26. Informação verbal: Entrevista sobre medievalismo concedida a Marco Bin e Mônica Nunes no $17^{\circ}$ Encontro Folk de SP, no Parque da Água Branca, em São Paulo, em 9 de fevereiro de 2019.

27. MONTEIRO, Gabriela. A cena expandida: alguns pressupostos para o teatro do século XXI. Art Research Journal, Natal, v. 3, n. 1, p. 37-49, 2016.

28. ELIADE, Mircea. O sagrado e o profano Lisboa: Edições Livros do Brasil, [19--]. 
29. FRANCO JUNIOR, Hilário. A Idade Média, o nascimento do Ocidente. São Paulo: Editora Brasiliense, 1986, p. 153

\section{Ibidem, p. 156.}

31. Informação verbal: Entrevista sobre medievalismo concedida a Marco Bin e Mônica Nunes no $17^{\circ}$ Encontro Folk de SP, no Parque da Água Branca, em São Paulo, em 9 de fevereiro de 2019.

32. MORUS, Thomas. A utopia. São Paulo: Abril Cultural, 1978. (Coleção Os Pensadores).

\section{Ibidem, p. 204.}

34. JACOBY, Russel. Imagem imperfeita: pensamento utópico para uma época antiutópica. Rio de Janeiro: Civilização Brasileira, 2007, p. 214-215. "a interpretação hierofânica do universo se expressava especialmente através de práticas mágicas, isto é, de alterações da realidade visível graças a intervenções da realidade invisível" ${ }^{29}$.

Os folkers reproduzem o maravilhoso das lendas em seus cânticos, nas rodas de leituras líricas que fazem, em crenças nas manifestações profanas, transformando esses índices em rituais criados e recriados, à moda do que consideram o imaginário de uma época, e nesse sentido se aproximam das coisas vistas como hierofanias, "como algo a mais do que pareciam à primeira vista, uma cosmologia simbólica [que] se impunha com naturalidade"30.

Paralelamente à relação cósmica com as forças metafísicas do universo, é possível observar a busca por uma utopia, uma consciência política nos encontros, ainda que o termo política, em seu aspecto partidário, seja evitado pelas tensões vivenciadas desde as eleições presidenciais de 2018. Camila explica: "o encontro folk foi feito para ser utópico", deixando claro que os ritos pagãos - os encontros em espaços naturais que simulam florestas medievais, marcados pela música, pela declamação lírica, regados por comida e bebida - se manifestam simultaneamente com um cuidado contemporâneo e com a preservação do meio-ambiente, expressa na recolha compulsória do lixo produzido em cada encontro. Conforme Camila, "não teria sentido a gente vir aqui cultuar a natureza e deixar o lixo espalhado" ${ }^{\text {. O }}$. sentido utópico recupera o mundo de A utopia, de Tomas Morus, ao projetar um lugar ideal, ainda que no caso dos folkers contemporâneos esteja restrito a outro jeito de atuar politicamente no mundo, ou seja, resguardá-lo da poluição e, ao mesmo tempo, promover os sentidos do prazer, da diversão, do lúdico em cada encontro. É possível ouvir naquele pequeno espaço do parque da Água Branca as palavras de Rafael Hitloteu, o narrador de A utopia, ressoando em seu longo argumento sobre um lugar que proporciona o bem-estar de seus cidadãos livres, "na Utopia as leis são pouco numerosas, a administração distribui indistintamente seus benefícios por todas as classes de cidadãos [...], a riqueza é tão igualmente repartida que cada um goza abundantemente de todas as comodidades da vida" 32 .

Se temos a ação política legitimada na atenção aos dejetos descartados, ao cuidado explícito à poluição ambiental, ao fato de o "rolê ser de graça", como muitos disseram, que pode ser incorporada por todas as tendências do espectro político-partidário sem causar problemas entre os folkers, o mesmo não ocorre com questionamentos de ordem social e econômica, que poderiam surgir facilmente no transcorrer da prática cultural. Tal restrição por certo impede de se ouvir a continuidade da fala de Hitloteu em defesa da Utopia, a denunciar a miséria do povo, o rechaço da pena de morte, o respeito aos velhos e doentes, e enunciar que o "único meio de distribuir os bens com igualdade e justiça, e de fazer a felicidade do gênero humano, é a abolição da propriedade" ${ }^{33}$.

Jacoby $^{34}$, ao analisar o pensamento utópico na contemporaneidade, é veemente ao afirmar que "a ideia utópica precede um programa político [...], o problema hoje é como ligar o pensamento utópico com a política cotidiana. Como os sonhos sobre o 'que deveria ser' se relacionam com o 'que é'?", 
indaga-nos. Talvez esses grupos complexos e heterogêneos ofereçam algumas chaves de leitura. Para eles, especialmente os folkers (que em outros momentos podem ser steamers ou cosplayers), o que é se ancora na memória de um passado medieval conhecido midiaticamente, sonhado, inventado, isto é, fruto também do imaginário, de uma subjetividade compartilhada na própria memória da cultura: a natureza esplendorosa. Esta, hoje ameaçada pelo lixo, pelo plástico, por ações políticas predatórias que por um dia neutralizam e, desse modo, ligam o pensamento utópico ancorado na memória a uma política prática.

Mesmo aqui encontramos contrariedades. Ao imaginar um espaço de convivência utópico, portanto, seria indispensável a avaliação política que despertasse a ideia plena de felicidade, pautada na igualdade e justiça não só nas ações salvacionistas. Vários dos entrevistados se encontram desempregados ou em atividades profissionais precarizadas, mais próximos do que Morus chamava de ladrões, vagabundos e lacaios. De modo geral, os integrantes das teatralidades medievalistas, ao buscarem experimentações hierofânicas e utópicas, alinham-se a recriações livres dos comportamentos e costumes medievais, com o objetivo de desfrutar cada encontro. De outra parte, o drama das condições sociais vivido na realidade medieval ${ }^{35}$ não se reproduz no espaço lúdico, utópico. A evasão das tensões contemporâneas e o prazer em conexão com a natureza garantem que os eventos medievalistas sejam experimentados como um mundo à parte.

\section{MEDIEVALISMO E POLÍTICA}

O jogo performático era de algum modo esperado naquele contato. Bruno Marcelo, 22 anos, desempregado, outro dos organizadores do Encontro Folk SP 2019, confirmou o propósito principal de estarem ali e fazer "um evento gratuito para a galera, o pessoal vem, toca música junto, conversa sobre o medievalismo, se diverte". Propostas genéricas a indicar ampla liberdade de ação, se considerarmos outros grupos medievalistas entrevistados, como o Graal ou o Draikaner, que tinham no combate o eixo principal de suas práticas culturais.

No texto de Nappo sobre o grupo Draikaner, podemos observar o quanto a disciplina está presente nas práticas dos combates do swordplay, mais além, o desejo de reproduzir personagens das crônicas de Artur, "cavaleiros heroicos, que lutam com honra e dedicação e que através de suas habilidades e por suas retidões de caráter conseguem a vitória" ${ }^{36}$. Mais adiante, ao descrever a classificação dos jogos em Callois, Nappo destaca a categoria Âgon como a forma pura do mérito pessoal, firmando a relação com os combatentes. Âgon "nos ajuda a entender algo que surge com muita força nas entrevistas com os participantes do Draikaner, a importância do lema do grupo, In Gladius Victoria Est, a vitória está na espada, que traduz os princípios da justiça e da meritocracia na prática do boffering no grupo"; e completa sobre o reconhecimento da excelência alcançada no combate: "entendem que só conseguirão esse reconhecimento com uma atenção persistente, treinos apropriados, assiduidade e vontade de vencer" ${ }^{37}$.

35. DUBY, Op. cit. 36. NAPPO, Op. cit., p. 47. 37. Ibidem, p. 53. 
38. Informação verbal: entrevista sobre medievalismo concedida a Marco Bin, Mônica Nunes e Davi de Sá em trabalho de campo referente à pesquisa Comunicação, Consumo e Memória: da cena cosplay a outras teatralidades juvenis, no Anime Family, Rio de Janeiro, em 1 de agosto de 2015.

39. DARDOT, Pierre; LAVAL, Christian. A nova razão do mundo: ensaio sobre a sociedade neoliberal. São Paulo: Boitempo Editorial, 2016, p. 9

40. GAGO, Verónica. A razão neoliberal: economias barrocas e pragmática popular. São Paulo: Editora Elefante, 2018, p. 233
Sob o manto do mundo imaginário de Vento Verde, criação do Larp pelo grupo medievalista Graal (RJ), é possível constatar a inter-relação dos mundos real e lúdico ou. de modo mais objetivo, os benefícios psíquicos da brincadeira quando levadas ao mundo real do trabalho. Luiz Vitório, 23 anos, empregado em um centro de atendimento, a certa altura de sua entrevista comenta que as atividades no grupo permitem "descarregar a frustração, dá para fingir que é outra pessoa tranquilamente, você acaba se tornando outra pessoa naquele momento". $\mathrm{E}$, ao prosseguir em sua fala, demonstra o quanto as experiências lúdicas são aproveitadas na realidade da vida cotidiana:

o meu trabalho é estressante, ai eu levei umas armas, dessas armas de espuma, só que maiores. Pessoal, vamos desestressar um pouquinho? Vamos cair na bolacha, brincar um pouquinho? Não tem que bater forte, mas 15 minutinhos desestressou todo mundo, melhora o rendimento no trabalho do pessoal, o pessoal se diverte, pergunta quando vou fazer de novo. Eu tento toda semana fazer isso, toda semana ${ }^{38}$.

É perceptível nos dois casos a presença de uma ordem que transcende a experiência medievalista, reproduzindo - no primeiro caso de modo explícito, no segundo caso de modo implícito - os ditames de uma ordem produtiva, pautada pela lógica do capital a todas as camadas sociais. Por mais que as coletividades lúdicas queiram incorporar modos de ser do tempo medieval, como a honra e a vitória pela espada, compreendendo-os como referências importantes do ponto de vista ético e moral que julgam perdidas no tempo presente, a reprodução desses modos de ser medieval expressa a inescapável vinculação desses participantes ao sistema normativo neoliberal. Assim, a brincadeira atua como uma sutil extensão do que vivemos na realidade social neoliberal, a começar pelo enfraquecimento dessa própria vivência coletiva, visto que os indivíduos "são submetidos a um regime de concorrência em todos os níveis"39.

Observamos dois aspectos decisivos: a subjetividade e a sujeição. A subjetividade compreende e incorpora a força moral da sujeição ao sistema normativo neoliberal, assim, o lema "a vitória está na espada", do grupo Draikaner, inspira o comportamento de seus participantes, como Vitor, 17 anos, estudante, quando diz que, para conquistar a vitória, tem de ser apenas pela espada, pelo combate, pelo suor. Em suma, a conquista em seu trabalho se define pela luta e, consequentemente, por seu mérito, e deixa explícita a vontade individual como determinação para alcançar um objetivo. No caso de Luiz Vitório, o sacrifício realizado no trabalho ao longo da semana encontra na prática lúdica do boffering, por 15 minutos, uma saudável maneira de "desestressar". Não é a dinâmica da gestão empresarial que é quebrada a partir de uma consciência política da exploração trabalhista, mas um breve intervalo permitido de pausa e entretenimento para a retomada revigorante do trabalho produtivo. A organização desses grupos medievalistas se encaixa perfeitamente na gestão empresarial. Em outras palavras, a luta, a honra, a disciplina, a vitória pela espada, equivalem à liberdade concorrencial do estado sob a vigilância do mercado, que concede "a cada um uma espécie de espaço econômico dentro do qual podem assumir e enfrentar os riscos" ${ }^{\prime 4}$. 
A racionalidade neoliberal não se resume à conversão dos espíritos. Isso não seria suficiente para o estabelecimento profundo de uma nova ordem comportamental, mas “obra, em grande parte, de técnicas e dispositivos de ordenação, isto é, de sistemas de coação, tanto econômicos como sociais, cuja função era obrigar os indivíduos a governar a si mesmos sob a pressão da competição"41. Assim, não basta se convencer da inevitabilidade de um sistema normativo, mas aceitá-lo como orientação dos desejos individuais. Se tomarmos essa lógica, poderemos compreender com clareza que a conduta no neoliberalismo cria as pontes para seu prolongamento ético e moral nas teatralidades das memórias medievalistas ou, como destacam Dardot e Laval,

Serão construídos sistemas de controle e avaliação de conduta cuja pontuação condicionará a obtenção das recompensas e a evitação das punições. A expansão da tecnologia avaliativa como modo disciplinar repousa sobre o fato de que quanto mais livre para escolher é supostamente o indivíduo calculador, mais ele deve ser vigiado e avaliado para obstar seu oportunismo intrínseco e forçá-lo a conjuntar seu interesse ao da organização que o emprega ${ }^{42}$.

Se abstrairmos o significado econômico da afirmação apresentada e considerarmos seu aspecto moral, podemos facilmente aplicar o conceito subjacente à política da meritocracia presente no grupo Draikaner, ou à disposição disciplinar no comportamento profissional de Luiz Vitório. E podemos inferir o porquê dos limites da realização do pensamento utópico não apenas na proposta do Encontro Folk, mas em qualquer outra proposta de ação social em nossa contemporaneidade. No momento neoliberal em que vivemos, a soberania da reterritorialização no corpo $^{43}$ consagra os interesses das normas pessoais para o seu sucesso. A dificuldade não nos parece de ordem prática, mas ideológica, no sentido mais nato da palavra, ao entendermos que no neoliberalismo devem prevalecer valores como a competição e a produtividade.

Por outro lado, não nos parece suficiente a condenação do sistema normativo sem uma compreensão de que a racionalidade neoliberal, como expressão do capitalismo financeiro, com seus excessos e privações, se estabelece como consenso "na nova ordenação das atividades econômicas, das relações sociais, dos comportamentos e das subjetividades" ${ }^{4}$. As teatralidades dos jovens medievalistas não escapam a esse contexto.

\section{CONSIDERAÇÕES FINAIS}

Procuramos mostrar neste trabalho as possíveis relações entre a memória, a utopia e a política. Vale lembrar que, neste caso, tanto o passado como suas memórias são textos da cultura, isto é, em projeção no tempo e dotados eles mesmos de um tempo interno.

Reconhecemos nesse tempo interno o pulsar utópico das manifestações teatralizadas, que alimentam o sonho de uma felicidade ligada à natureza, como nos mostrou a flânerie realizada no Encontro Folk SP. "Cultuar e resgatar

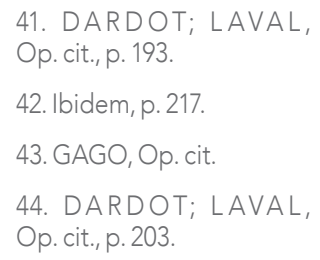


comunicação \& educação • Ano XXV • número 2 • jul/dez 2020

a natureza", "reverenciar os deuses" foram as frases mais reportadas pelos participantes. Sinalizam um desejo utópico e, como afirma Jacoby, "os desejos utópicos precisam ser situados em contraposição a algo ...], o utopismo demonstra coragem e audácia no sonho" ${ }^{\prime 5}$.

Ainda que a audácia esteja presente e que a natureza volte a ser um lugar vital a ser preservado para esses grupos, a racionalidade neoliberal, na força de sua ubiquidade, fragiliza o devaneio utópico - presa fácil do esvaziamento do debate político que ocorre atualmente em nosso país. As teatralidades expandidas da memória do medievalismo se imbricam aos paradoxos e contradições atuais que não poupam esses jovens.

\section{REFERÊNCIAS BIBLIOGRÁFICAS}

DARDOT, Pierre; LAVAL, Christian. A nova razão do mundo: ensaio sobre a sociedade neoliberal. São Paulo: Boitempo, 2016.

DIÉGUEZ, Ileana C. Um teatro sem teatro: a teatralidade como campo expandido. Sala Preta, São Paulo, v. 14, n. 1, p. 125-129, 2014.

DIÉGUEZ, Ileana C. Escenarios y teatralidades liminales. Prácticas artísticas y socioestéticas. Inquietando, [S. l. ], 2016. Disponível em: https://inquietando. wordpress.com/textos-2/escenarios-y-teatralidades-liminales-practicasartisticas-y-socioesteticas/. Acesso em: 14 fev. 2019.

DUBY, Georges. A Europa na Idade Média. São Paulo: Editora Brasiliense, 1988. ECO, Umberto. Viagem na irrealidade cotidiana. Rio de Janeiro: Nova Fronteira,1984.

ELIADE, Mircea. O sagrado e o profano. Lisboa: Edições Livros do Brasil, [19-]. FRANCO JUNIOR, Hilário. A Idade Média, o nascimento do Ocidente. São Paulo: Editora Brasiliense, 1986.

GAGO, Verónica. A razão neoliberal: economias barrocas e pragmática popular. São Paulo: Editora Elefante, 2018.

HUYSSEN, Andreas. Seduzidos pela memória. Rio de Janeiro: Aeroplano, 2000.

HUYSSEN, Andreas. Culturas do passado-presente: modernismos, artes visuais, políticas da memória. Rio de Janeiro: Contraponto, 2014.

JACOBY, Russel. Imagem imperfeita: pensamento utópico para uma época antiutópica. Rio de Janeiro: Civilização Brasileira, 2007.

LOTMAN, Iuri. La semiosfera. Catedra: Madrid, 1996. v. 1.

MACLAREN, Peter. Multiculturalismo revolucionário. Porto Alegre: Artmed, 2000. 
MONTEIRO, Gabriela. A cena expandida: alguns pressupostos para o teatro do século XXI. Art Research Journal, Natal, v. 3, n. 1, p. 37-49, 2016.

MORUS, Thomas. A utopia. São Paulo: Abril Cultural, 1978. (Coleção Os Pensadores).

NAPPO, Sami. De tabardo e espada em punho: consumo, memória e medievalismo em um grupo juvenil praticante de boffering. 2017. Dissertação (Mestrado em Comunicação e Práticas de Consumo) - Escola Superior de Propaganda e Marketing, São Paulo, 2017.

NUNES, Mônica Rebecca Ferrari. (org.). Cosplay, steampunk e medievalismo: memória e consumo nas teatralidades juvenis. Porto Alegre: Sulina, 2017.

NUNES, Mônica Rebecca Ferrari; BIN, Marco Antonio. Espartilhos e espadas: vitorianos e medievalistas em práticas juvenis. Revista Líbero, São Paulo, v. 19, n. 38, p. 69-80, 2016.

PASSERINI, Luisa. Memoria y utopia: la primacia de la intersubjetividade. Valencia: Publicacions de la Universitat de Valencia, 2006.

ZUMTHOR, Paul. Performance, recepção, leitura. São Paulo: Cosac Naify, 2007. 